\title{
NEW DERIVED CORRELATIONS FOR LIBYAN CRUDE OIL TO ESTIMATE BUBBLE-POINT PRESSURE
}

\author{
Mustafa Sharrad $^{1}$ and Hamid Hakim Abd-AIrahman ${ }^{2}$ \\ ${ }^{1,2}$ Dept. of Chemical and Petroleum Engineering, Sabratha Faculty of Engineering, Sabratha University, \\ Sabratha, Libya \\ Corresponding author Tel: +218 (91) 336 0955, msharrad1@ gmail.com
}

\begin{abstract}
The key factor of all petroleum engineering calculation is the knowledge of the PVT (Pressure, Volume, Temperature) parameters, such as determination of oil and gas flowing properties, predicting production performance in the future, production facilities designing and enhanced oil recovery planning methods. Those PVT properties are ideally determined experimentally in the laboratory. However, some of these experimental data is not always available; consequently, empirical correlations are used to estimate them. Many researchers have been focusing on models for predicting reservoir fluid properties from the available experimental PVT data, such as reservoir pressure, temperature, crude oil API gravity, gas oil ratio, formation volume factor, and gas gravity. The present study compares between some of the available empirical PVT correlations for estimating the bubble point pressure of some Libyan crude oils based on 35 data point samples from different Libyan oil fields. In the second part of this study, a new correlation has been derived to predict the bubble point pressure using Eviews software and compares the output results of this new correlation with some derived correlations found in the literature using statistical analysis such as the Average Absolute Error (AARE). The results showed an AARE as low as $8.7 \%$, for bubble point pressure estimated by this new derived correlation. These results are valid to compare to other driven empirical correlations that have been evaluated.
\end{abstract}

Keywords: PVT properties, Empirical Correlations, Bubble point pressure.

\section{Introduction}

Crude oil physical and chemical properties are varying considerably depending on the crude oil composition, and the concentration of the various types of hydrocarbons and minor constituents present (Ahmed, T., 2010). An accurate determination of crude oil physical properties is important in solving the petroleum engineering problems. The most physical properties important for the petroleum engineering calculations include fluid gravity, specific gravity of the solution gas, gas solubility, bubble-point pressure, oil formation volume factor, isothermal compressibility coefficient of under-saturated crude oils, oil density, total formation volume factor, crude oil viscosity, and surface tension (Ahmed, T., 2010). PVT properties are commonly measured experimentally in the laboratory from an actual reservoir fluid samples. In the absence 
of any of those experimentally measured data of crude oils; it will be necessary for the petroleum engineer to estimate or determine the missing properties from empirically derived correlations.

Those mathematically developed PVT correlations used in the petroleum industry are essential tools in reservoir-performance calculations. To develop a PVT correlation, the considerations of the geological condition must be considered due to the variation of the chemical composition of crude oil from region to region. There are too many wide range available PVT correlations used worldwide, therefore, it is valuable to evaluate them for a given set of PVT data of a certain geological region. Many researchers have reviewed those correlations and tried to apply them for different regions, there were unsatisfactory output results when they used correlations derived from data of a certain region to another crude oil system in another region because of the differences in composition (Sharrad, M. and Abdussalam, T. 2015).

This study focuses on deriving a new correlation to estimate the Bubble Point Pressure, $P_{b}$, for the Libyan crude oils using available 35 data point samples from different Libyan oil fields, then compare the results obtained from some known PVT correlations found in the literature.

\section{The bubble-point pressure $P_{b}$ : Literature Review}

A group of several known PVT correlations have been chosen as a part of our comparative study. These correlations used also to compare with the newly developed correlation.

During the last decay, several correlations have been published for estimating PVT properties. Most of the widely used correlations are dealing with the oil and gas phases as a two-phase system (Wu, R. and Rosenegger, L., 1999).

The bubble-point pressure $\mathrm{P}_{b}$ of a hydrocarbon system is defined as the highest pressure at which a first bubble of gas is liberated from the oil (Ahmed, T., 2010).

The simple form of different derived correlations for oil phase PVT properties is derived from Standing's initial equation as:

$$
p_{b}=f\left(R s, \gamma_{g}, \gamma_{o}, T\right)
$$

Therefore, the required data for input to any correlations include gas solubility $\left(R_{S}\right)$, gas specific gravity $\left(\gamma_{g}\right)$, oil specific gravity $\left(\gamma_{o}\right)$, and reservoir temperature $(T)$ and a specified range of pressure. The first three parameters, $R_{S}, \gamma_{g}$, and $\gamma_{o}$, are referred to either separator or stock tank conditions for all correlations (Whitson, C. H., 1998).

More than 30 methods have been proposed for the Correlations of bubble-point pressure since Standing's correlation had appeared in 1947. Most of them were developed during the last 15 years. The efficient use of those correlations lies in an understanding of their derivation, along with knowledge of their limitations (Wu, R. and Rosenegger, L., 1999). This study focused on some of the famously published correlations as described below: 


\section{Standings Correlation}

Standing (1947) proposed his first correlation in a graphical form for determining the bubblepoint pressure of crude oil systems based on 105 experimentally measured bubble-point pressures data points from 22 hydrocarbon systems from California oil fields. His proposed correlation was correlating these parameters; gas solubility $\boldsymbol{R}_{\boldsymbol{s}}$, gas gravity $\boldsymbol{\gamma}_{g}$, oil $\boldsymbol{A P I}$ gravity, and the system temperature $\boldsymbol{T}$. (Godefroy, et al., 2012).

In 1981 Standing expressed his graphical correlation in the mathematical form in the following expression (Godefroy, et al., 2012):

$$
P_{b}=18.2\left(R s / \gamma_{g}\right)^{0.83}\left[(10)^{a}-1.4\right]
$$

With

$$
a=0.00091(T-460)-0.0125(A P I)
$$

Where

$$
\begin{gathered}
\boldsymbol{P}_{b}=\text { bubble-point pressure, } p \text { sia } \\
\boldsymbol{T}=\text { reservoir temperature, }{ }^{\circ} \boldsymbol{R} .
\end{gathered}
$$

\section{Glaso's Correlation (1980)}

Glaso (1980) used 45 oil samples, mostly from the North Sea hydrocarbon system, to develop an accurate correlation for bubble-point pressure prediction. Glaso proposed the following expression:

$$
\log \left(P_{b}\right)=1.7669+1.7447 \log \left(P_{b}^{*}\right)-0.30218\left[\log \left(P_{b}^{*}\right)\right]^{2}
$$

Where: $\boldsymbol{P}_{\boldsymbol{b}}^{*}$ is a correlating number and defined by the following equation:

$$
p_{b}^{*}=\left(R_{S} / \gamma_{g}\right)^{a}(T)^{b}(A P I)^{c}
$$

Where

$\boldsymbol{R}_{s}=$ gas solubility, $s c f / S T B$

$\boldsymbol{T}=$ system temperature, ${ }^{\circ} \boldsymbol{F}$

$\gamma_{g}=$ average specific gravity of the total surface gases

$\mathrm{a}, \mathrm{b}, \mathrm{c}=$ coefficients of the above equation having the following values:

$$
\mathrm{a}=0.816, \quad \mathrm{~b}=0.172, \quad \mathrm{c}=-0.989
$$

For volatile oils, Glaso recommended that the temperature exponent (b) be slightly changed, to the value of 0.130 (Oloruntoba, F. M. and Onyekonwu M., O. 2016). 


\section{Marhoun's Correlation (1988)}

Marhoun in 1988 developed a correlation from 160 experimentally determined bubble-point pressures from 69 Middle Eastern hydrocarbon systems for estimating $\boldsymbol{P}_{\boldsymbol{b}}$ in the absence of the laboratory measured one. The author correlated the bubble-point pressure with the gas solubility $\boldsymbol{R}_{\boldsymbol{s}}$ reservoir temperature $\boldsymbol{T}$, and specific gravity of the oil and the gas (Ahmed, T., 2010). Marhoun proposed his correlation as in the following expression:

$$
P_{b}=a R_{S}^{b} \gamma_{g}^{c} \gamma_{o}^{d} T^{e}
$$

Where

$$
\begin{aligned}
& T=\text { temperature, }{ }^{\circ} \boldsymbol{R} \\
& \gamma_{\boldsymbol{o}}=\text { stock-tank oil specific gravity } \\
& \gamma_{\boldsymbol{g}}=\text { gas specific gravity } \\
& \text { a }- \text { e }=\text { coefficients of the correlation having the following values: }
\end{aligned}
$$$$
a=5.38088 \times 10^{-3} \quad b=0.715082 \quad c=-1.87784 \quad d=3.1437 \quad e=1.32657 .
$$

The reported average absolute relative error for the correlation was 3.66\% when compared with the experimental data used to develop the correlation (Ahmed, T., 2010).

\section{The Vasquez-Beggs Correlation (1980)}

Vasquez and Beggs correlated results from more than 600 oil systems to develop empirical correlations for several oil properties which bubble-point pressure is included. The data covered very wide ranges of the correlated parameters; pressure, oil specific gravity, temperature, and gas specific gravity, where about 6,000 measured data points were included for $\boldsymbol{R}_{\boldsymbol{s}}, \boldsymbol{B}_{\boldsymbol{o}}$, and $\boldsymbol{\mu}_{\boldsymbol{o}}$ at various pressures and temperatures. The gas specific gravity was found a strong correlating parameter (Hemmati M. N. and Kharrat, R., 2007).

The gas specific gravity used to develop all the correlations published by Vasquez and Beggs was collected from a two-stage separation. The first-stage pressure was $100 \mathrm{psig}$ and the second stage was the stock tank which is the atmospheric pressure (Hemmati M. N. and Kharrat, R., 2007).

$$
P_{b}=\left[\left(C 1 R_{S} / \gamma_{g s}\right)(10)^{a}\right]^{C 2}
$$

With

$$
a=-C 3 A P I / T
$$

$$
\gamma_{g s}=\gamma_{g}\left[1+5.912 \times 10^{-5}(A P I)\left(T_{s e p}-460\right) \log \left(\frac{p_{s e p}}{114.7}\right)\right]
$$

The gas specific gravity $\gamma_{g s}$ at the reference separator pressure is defined the coefficients $\mathrm{C} 1, \mathrm{C} 2$, and C3 have the following values (Ahmed, T., 2010): 
Table (1): coefficients of Vasquez-Beggs bubble-point pressure Correlation

\begin{tabular}{|c|c|c|}
\hline Coefficient & API $\leq \mathbf{3 0}$ & API $>$ 30 \\
\hline C1 & 27.624 & 56.18 \\
\hline C2 & 0.914328 & 0.84246 \\
\hline C3 & 11.172 & 10.393 \\
\hline
\end{tabular}

\section{The Petrosky-Farshad Correlation (1993)}

In 1993 Petrosky and Farshad developed a new empirical correlation to predict bubble-point pressure in the absence of the experimental data. They used 81 laboratory PVT analyses of the Gulf of Mexico crude oils. The database used was constructed from two-stage separator laboratory test at bubble-point pressure. Their bubble-point pressure correlation used the same type of relationship as developed by Standing (1947) (Oloruntoba, F. M. and Onyekonwu M. O., 2016). The correlation of predicting bubble point pressure as:

$$
\begin{gathered}
P_{b}=\left[\frac{112.727 R_{S}^{0.577421}}{\gamma_{g}^{0.8439}(10)^{x}}\right] \\
x=7.916 \times 10^{-4}(A P I)^{1.5410}-4.561 \times 10^{-5}(T-460)^{1.3911}
\end{gathered}
$$

Where $\quad \boldsymbol{P}_{\boldsymbol{b}}=$ Bubble point pressure, $\boldsymbol{p s i \boldsymbol { a }}$

$$
\boldsymbol{T}=\text { System temperature }{ }^{\circ} \mathrm{R} \text { (Ahmed, T., 2010). }
$$

\section{Dokla - Osman Correlation (1992)}

Dokla and Osman in 1992 developed correlation to predict and estimate the bubble point pressure from the available PVT data from UAE reservoirs, the correlation has the form:

$$
P_{b}=0.836386 \times 10^{4} \gamma_{g}^{-1.01049} \gamma_{o}^{0.107991} T^{-0.952584} R_{S}{ }^{0.724047}
$$

$\boldsymbol{T}=$ system temperature, $\boldsymbol{R}^{\circ}$ (Hemmati M. N. and Kharrat, R., 2007).

\section{AI-Shammasi Correlation (1999)}

Al-Shammasi in 1999 compared different published correlations using 1243 measurements from global data bank found in the literature. A new correlation for estimating bubble-point pressure was developed by exploring the relationship between the different variables and measurements through graphical means and linear regression, to improve the performance he compared to earlier published data (Oloruntoba, F. M. and Onyekonwu M. O., 2016).

$$
P_{b}=\gamma_{o}^{5.527215} \exp \left(-1.8411408\left(\gamma_{o} \gamma_{g}\right)\right) \cdot\left(R_{S}(T+460) \gamma_{g}\right)^{0.783716}
$$


Where:

$\boldsymbol{P}_{\boldsymbol{b}}=$ bubble-point pressure, $\boldsymbol{p s i a}$

$\boldsymbol{R}_{\boldsymbol{S}}=$ solution gas- oil ratio $(\boldsymbol{s c f} / \mathrm{STB})$,

$\gamma_{g}=$ dissolved gas relative density $($ air $=1)$,

$\boldsymbol{A P I}=$ stock-tank oil gravity,

$\boldsymbol{T}=$ reservoir temperature $\left({ }^{\circ} \boldsymbol{F}\right)$,

$\gamma_{\boldsymbol{o}}=$ specific gravity of the stock-tank oil

Range of data used in the previous study and in this one illustrated in the following table (2).

Table (2): Range of data used for different correlations

\begin{tabular}{|c|c|c|c|c|}
\hline Correlation Name & $\begin{array}{c}\mathbf{P}_{\mathbf{b}} \\
(\mathbf{p s i a})\end{array}$ & gas gravity & API & $\begin{array}{c}\text { T } \\
(\mathbf{F})\end{array}$ \\
\hline Standing & $130-7000$ & $0.59-0.95$ & $16.5-63.8$ & $100-258$ \\
\hline Glaso & $150-6641$ & $0.65-1.276$ & $22.3-48.1$ & $80-280$ \\
\hline Marhoun & $121-6557$ & $0.725-1.367$ & $19.4-44.6$ & $74-240$ \\
\hline Vasquez-Beggs & & & & \\
\hline Petrosky-Farshad & $1574-6523$ & $0.578-0.852$ & $16.3-45$ & $114-288$ \\
\hline Hemmati \& Kharrat & $348-5156$ & $0.523-1.415$ & $18.8-48.34$ & $77.5-290$ \\
\hline This Study & $179-3332$ & $0.676-1.062$ & $31.93-44.34$ & $117-309.7$ \\
\hline
\end{tabular}

The calculations of new Libyan crude oil PVT correlations

\section{Software used in this study}

\section{i. Microsoft Excel}

The Microsoft Excel was used in the comparison study between the different correlations have been studied, and used as an input data file to the EViews software.

\section{ii. EViews Software}

EViews can be used for general statistical analysis and econometric analyses, such as crosssection and panel data analysis and time series estimation and forecasting. In this study this software used to correlate the different parameters to develop the new correlation. 


\section{Bubble-point pressure Correlation Development}

The mathematical method used was least squares (LS); which is a standard approach in regression analysis to the approximate solution of over determined systems, the first expression by Roger Cotes in 1722 (Ahmed, T., 2010).

We find the relation and effect of this parameters $\left(\boldsymbol{R}_{\boldsymbol{s}}, \boldsymbol{\gamma}_{\boldsymbol{g}}, \boldsymbol{A P I}, \boldsymbol{T}\right)$ on $\boldsymbol{P}_{\boldsymbol{b}}$ was evident, where API larger standard error (SE) 0.379536 and lower is T 0.000557.

The experimentally determined bubblepoint pressures obtained from PVT analyses of 35 different Libyan fields.

The new derived correlation for bubble-point pressure as the following:

$$
\begin{gathered}
P_{b}=275.3878578 \times R_{S}^{0.600065268242} \times \gamma_{g}^{-2.44603416074} \times A P I^{-1.0621409305} \\
\times e^{0.00573453967684 \times T}
\end{gathered}
$$

Where:-

$\boldsymbol{P}_{\boldsymbol{b}}=$ bubble-point pressure (psia),

$\boldsymbol{R}_{\boldsymbol{s}}=$ solution gas- oil ratio $(\operatorname{scf} / \mathrm{STB})$,

$\gamma_{g}=$ dissolved gas relative density $($ air $=1)$,

$\boldsymbol{A P I}=$ stock-tank oil gravity,

$\boldsymbol{T}=$ reservoir temperature $\left({ }^{\circ} \mathrm{F}\right)$.

\section{Results and Discussion}

This section illustrates the results of this study. The comparison study of the most known correlations discussed in section two of this study, and the results obtained from our new correlation to estimate the Bubble Point Pressure has been targeted in this study.

The Statistical Analysis techniques used to compare the results collected from the correlations studied are the absolute average relative error (AARE), cross - plot, and $\boldsymbol{R}^{2}$.

\section{Bubble-point pressure correlations compare}

\section{Statistical Analysis techniques}

The correlation coefficient denoted $\mathrm{R}^{2}$ is a coefficient that illustrates a quantitative measure of some type of correlation and dependence, meaning statistical relationships between two or more random variables or observed data values can be calculated using the Microsoft Excel or from the following relationship: 


$$
\begin{gathered}
R^{2}=1-\left[\frac{\sum_{1}^{n}\left(X_{\text {actual value }}-X_{\text {measured value }}\right)^{2}}{\sum_{1}^{n}\left(X_{\text {actual value }}-\bar{X}\right)^{2}}\right] \\
\bar{X}=\frac{1}{n} \sum_{1}^{n}\left(X_{\text {actual value }}\right)_{i}
\end{gathered}
$$

Table (3) shows the data collected from the seven correlations of Bubble-point pressure have been chosen in this study compared with our correlation for Bubble-point pressure has been developed in this study.

The data showed that Petrosky - Farshad correlation has the highest $\boldsymbol{R}^{2}$ of 0.767 for all old correlations while AI-Shammasi has the lowest value of $\boldsymbol{R}^{2}$ of 0.451 , but when compared with $\boldsymbol{R}^{2}$ gained from our new developed correlation in this study, the new derived one found that it has higher $\boldsymbol{R}^{2}$ of 0.957 than the highest one of the old correlations and this was due to the difference of the chemical composition between the Libyan crudes and the others used to derive the other correlations.

Table (3): Statistical Analysis $\mathbf{R}^{2}$ Value of Bubble-point pressure correlations

\begin{tabular}{|c|c|}
\hline Correlation & $\boldsymbol{R}^{2}$ Value \\
\hline Standing & 0.6964 \\
\hline Glaso & 0.6911 \\
\hline Marhoun & 0.6637 \\
\hline Vasquez-Beggs & 0.7265 \\
\hline Petrosky-Farshad & 0.7673 \\
\hline Dokla and Osman & 0.4555 \\
\hline Al-Shammsi & 0.4514 \\
\hline Our New Derived Correlation & 0.9572 \\
\hline
\end{tabular}

Figure (1) shows the AARE of all studied correlations including our one. The data illustrate that, the lowest value of AARE has been recorded from all old correlations was $37.22 \%$ which obtained from Standing's correlation, while our new developed correlation gives lower value of the AARE of $8.7 \%$ than the lowest one of the old correlations as illustrated above in the range of available experimental data could collect in this study. 


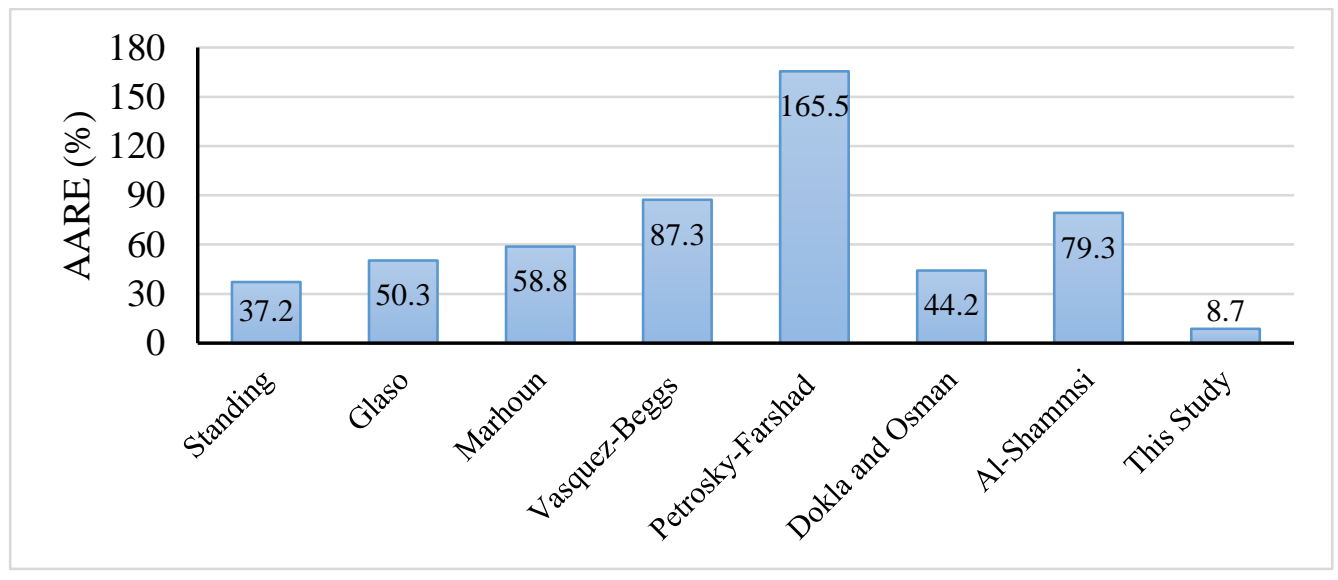

Figure (1): AARE\% Value of Bubble-point pressure correlations

\section{Cross-Plot Graphics Analysis}

Figures (2) to (8) show the cross-plot graphs plotted for all old targeted correlations studied. The vertical axis represents the calculated data from correlations, and the horizontal axis represents the experimental data and $45^{\circ}$ Line crossing two axes to shows the imaginary path for ideal data.

Notice figure (2) for Standing's correlation cross - plot shows that the calculated data was closer to the $45^{\circ}$ line than the other six old correlations, while the calculated results collected from AlShammasi's correlation the farthest to $45^{\circ}$ line.

By looking to Figure (9), which revealed the estimated bubble point pressure from our new developed correlation, you can notice that the data was closer to the $45^{\circ}$ line which means that the data closer to the reality more than other data had been calculated from other targeted correlation in this study in the range of available experimental data in this study.

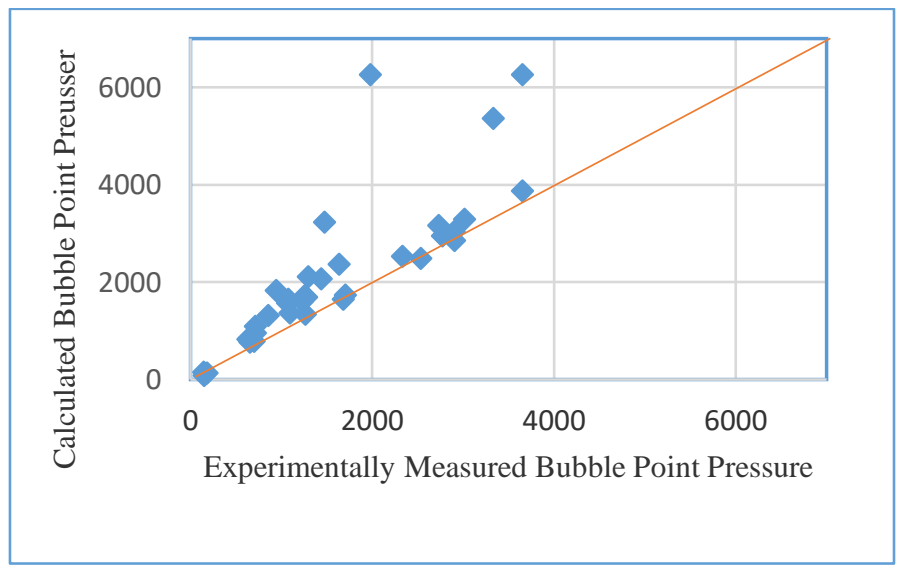

Figure (2): Cross-Plot of Standing Correlation Data V.S Measured Data of Bubble-Point Pressure Correlation 


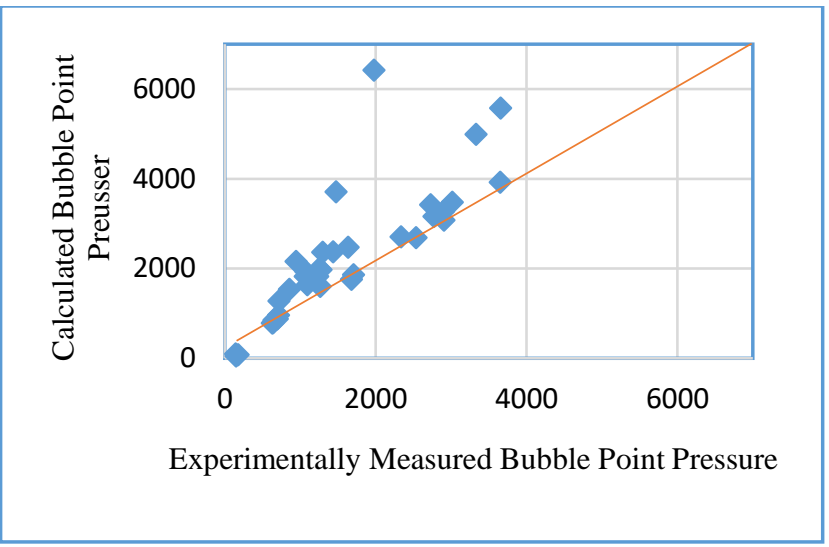

Figure (3): Cross-Plot of Glaso correlation data V.S measured data of Bubble-point pressure correlation

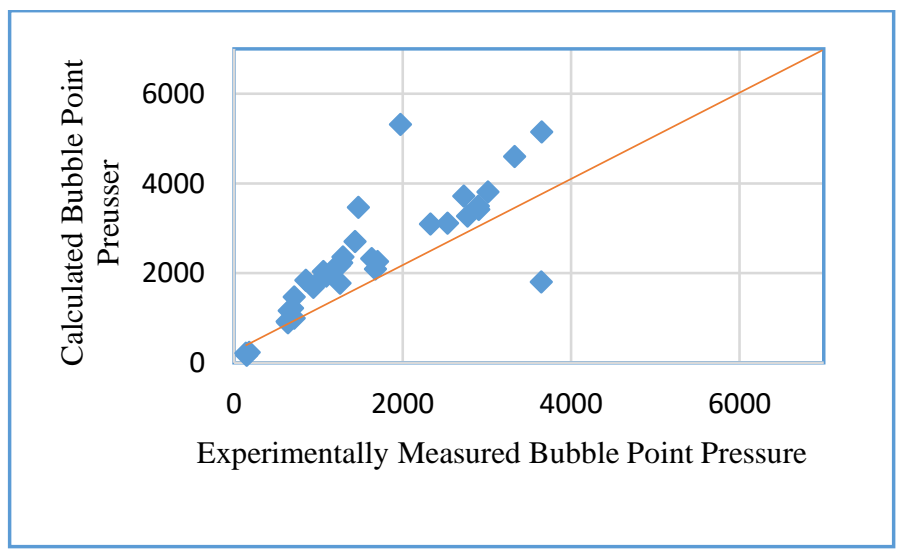

Figure (4): Cross-Plot of Marhoun Correlation Data V.S Measured Data of Bubble-Point Pressure Correlation

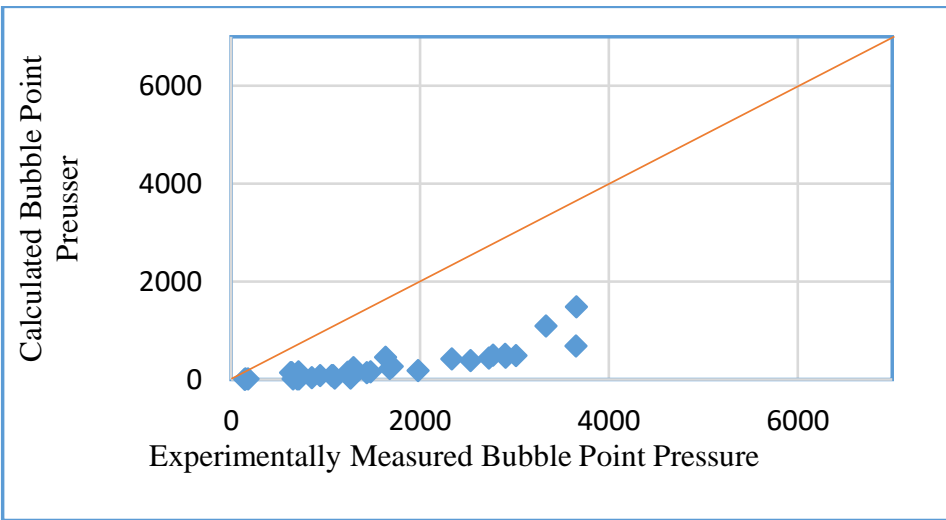

Figure (5): Cross-Plot of Vasquez-Beggs Correlation Data V.S Measured Data of Bubble-Point Pressure Correlation 


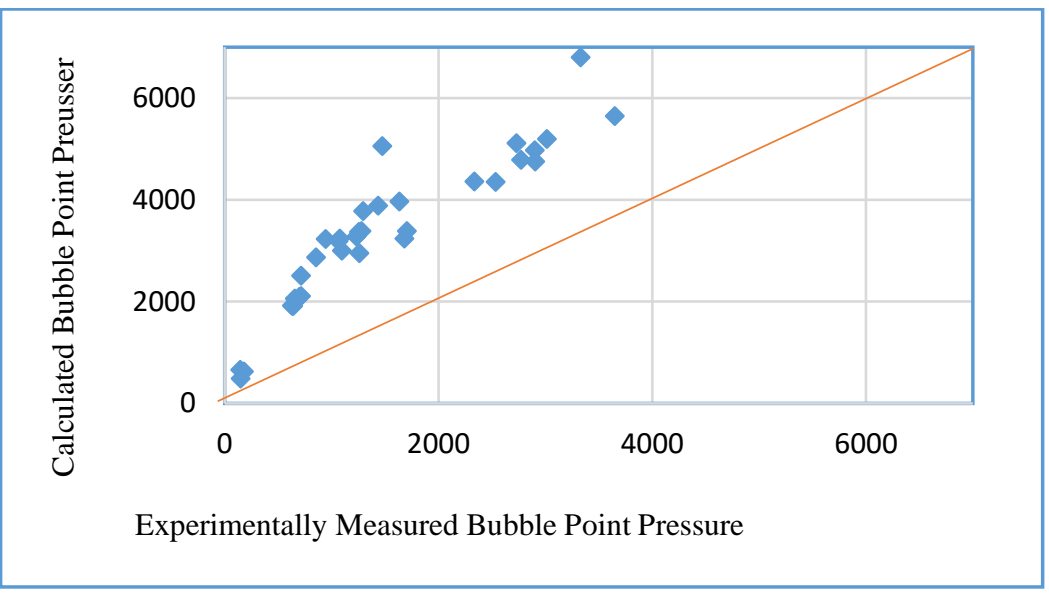

Figure (6): Cross-Plot of Petrosky-Farshad Correlation Data V.S Measured Data of Bubble-Point Pressure Correlation

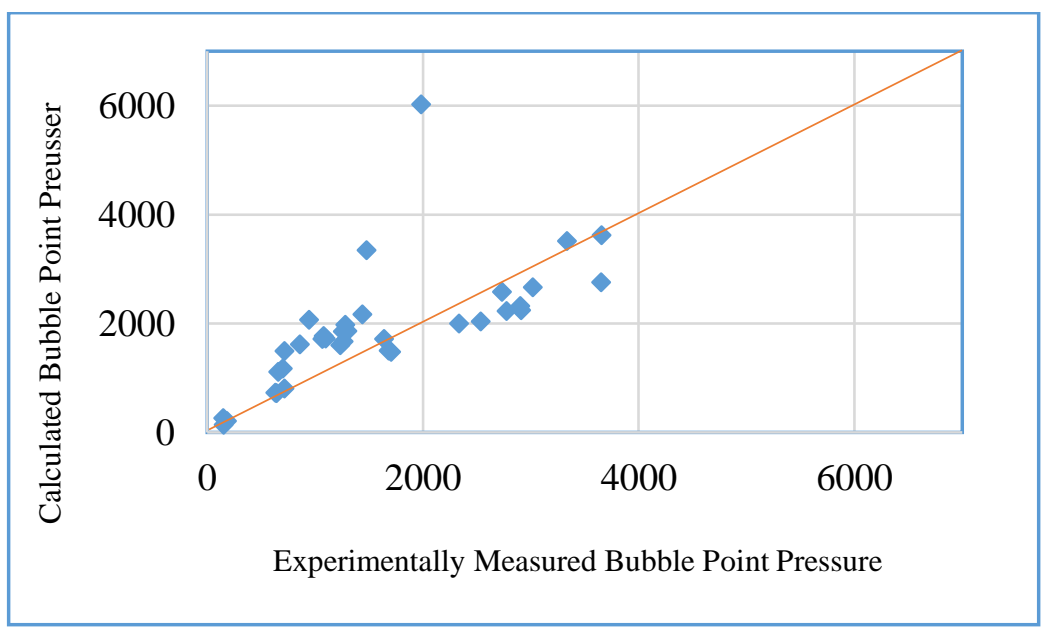

Figure (7): Cross-Plot of Dokla-Osman Correlation Data V.S Measured Data of Bubble-Point Pressure Correlation

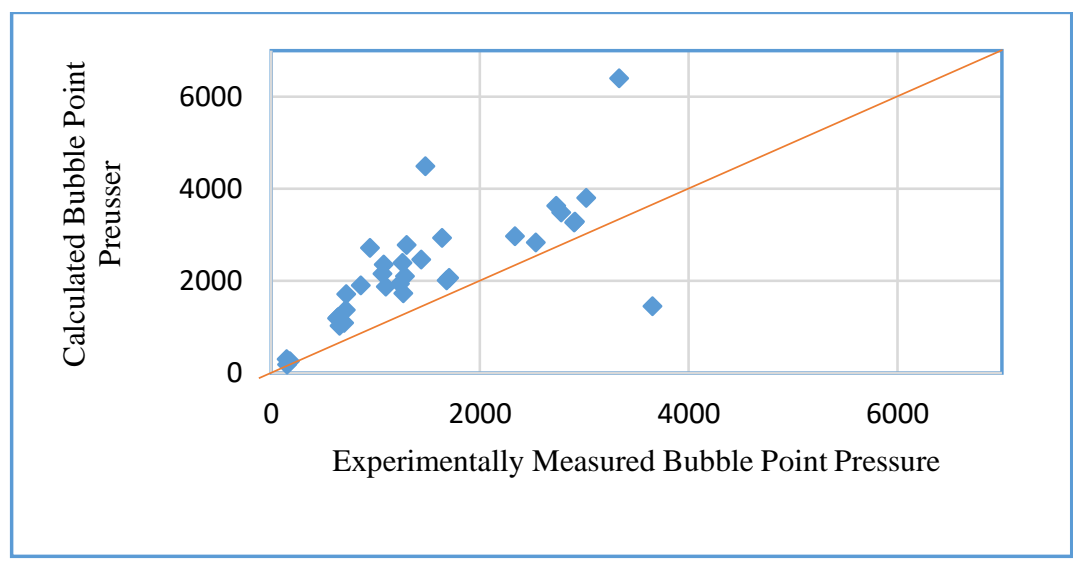

Figure (8): Cross-Plot of AI-Shammasi Correlation Data V.S Measured Data of Bubble-Point Pressure Correlation 


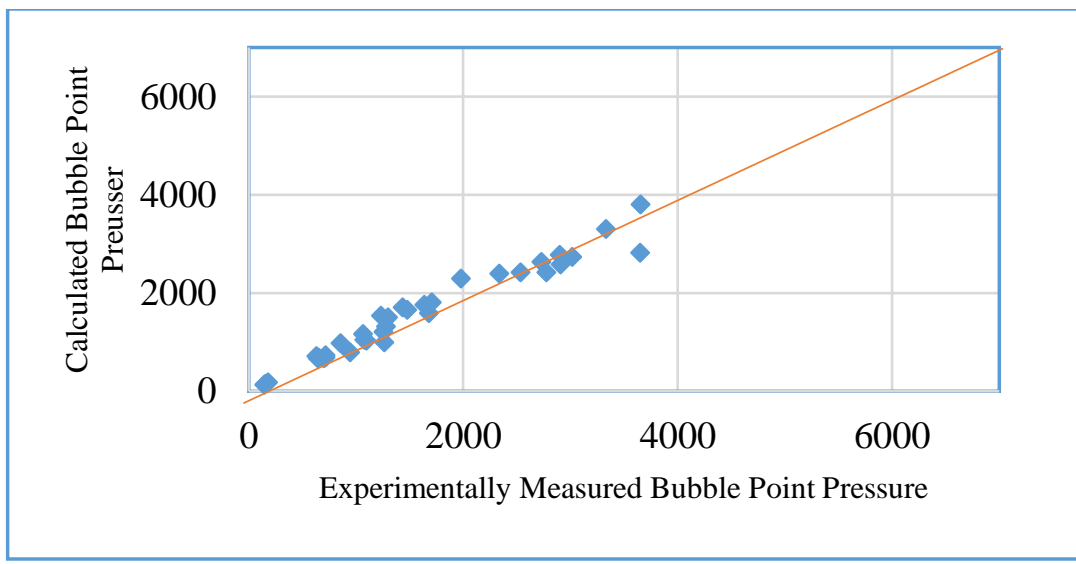

\section{Figure (9): Cross-Plot of This Study Correlation Data V.S Measured Data of Bubble-Point Pressure Correlation}

\section{Conclusions}

Based on the results obtained in this study, the following conclusions are obtained:

1. A new empirical correlation for Libyan crude oils has been developed for predicting the bubble point pressure.

2. The new bubble point correlation provided the highest accuracy of the correlations evaluated with the lowest absolute average relative error.

3. This correlation was developed specifically for Libyan crude oils but can be used for estimating the bubble-point pressure for all types of oil and gas mixtures with properties falling within the range of the data used in this study.

\section{References}

- Ahmed, T. H. (2010). Reservoir engineering handbook, fourth edition, USA: Gulf Professional Publishing

- Sharrad, M. and Abdussalam, T. (2015) Evaluation of Some Empirically Derived Correlations for Calculation of Oil Formation Volume Factor for Libyan Crude Oils, University Bulletin ISSUE No.17- Vol. (1) pages 5 - 26.

- Wu, R. and Rosenegger, L. (1999), Comparison of PVT Properties from Equation of State Analysis and PVT Correlations for Reservoir Studies, Petroleum Society Joint Convention, Alberta. Canada. June 14 - 18, 1999, 99-38. 
- Whitson, C. H. (1998), Fluid Sampling \& Laboratory Data .in: Norsk Hydro, Field Development \& Technology Reservoir Technology.

- Godefroy, S., Khor, S. H. and Emms, D. (2012), Comparison and Validation of Theoretical and Empirical Correlations for Black Oil Reservoir Fluid Properties, Offshore Technology Conference, OTC 22972, Houston, Texas, USA, 30 April-3 May 2012,1-26.

- Oloruntoba, F. M. \& Onyekonwu M. O. (2016), Empirical Prediction of Bubble Point Pressure and Solution Gas Oil Ratio for Niger Delta, International Journal of Scientific \& Engineering Research, ISSN 2229-5518, University of Port-Harcourt, Nigeria,1-11.

- Beggs, H. D. Oil System Correlations, in Petroleum Engineering Handbook.

- Hemmati M. N. and Kharrat, R. (2007), Evaluation of Empirically Derived PVT Properties for Middle East Crude Oils, Scientia Iranica, No. 4, Sharif University of Technology, August 2007,358-368.

- $\quad$ http://petrowiki.org/Oil bubblepoint pressure

- http://en.wikipedia.org/wiki/Linear_least_squares_(mathematics) 